\title{
Occupational exposure to organic solvents: a risk factor for pulmonary veno-occlusive disease
}

\author{
David Montani ${ }^{1,2,3,11}$, Edmund M. Lau ${ }^{1,2,3,11}$, Alexis Descatha ${ }^{4}$, Xavier Jaïs ${ }^{1,2,3}$, \\ Laurent Savale ${ }^{1,2,3}$, Pascal Andujar ${ }^{5}$, Lynda Bensefa-Colas ${ }^{6}$, Barbara Girerd ${ }^{1,2,3}$, \\ Inès Zendah ${ }^{7}$, Jerome Le Pavec ${ }^{9}$, Andrei Seferian ${ }^{1,2,3}$, Frédéric Perros ${ }^{1,2,3}$, \\ Peter Dorfmüller ${ }^{1,3,8}$, Elie Fadel ${ }^{1,3,9}$, Florent Soubrier ${ }^{10}$, Oliver Sitbon ${ }^{1,2,3}$, \\ Gérald Simonneau ${ }^{1,2,3}$ and Marc Humbert ${ }^{1,2,3}$
}

\begin{abstract}
Affiliations: ${ }^{1}$ Université Paris-Sud, Faculté de Médecine, Le Kremlin Bicêtre, France. ${ }^{2}$ AP-HP, Centre de Référence de l'Hypertension Pulmonaire Sévère, Département Hospitalo-Universitaire (DHU) Thorax Innovation (TORINO), Service de Pneumologie, Hôpital de Bicêtre, Le Kremlin Bicêtre, France. ${ }^{3}$ UMR_S999, Université ParisSud, INSERM, Laboratoire d'Excellence (LabEx) en Recherche sur le Médicament et l'Innovation Thérapeutique (LERMIT), Centre Chirurgical Marie Lannelongue, Le Plessis Robinson, France. ${ }^{4}$ AP-HP UVSQ, Occupational Health Unit/Population-Based Epidemiological Cohorts Unit, UMS 011-UMR 1168, University Hospital of Poincaré, Garches, France. ${ }^{5} \mathrm{CHI}$ Créteil, Service de Pneumologie et Pathologie professionnelle, Creteil, France. ${ }^{6}$ Paris Descartes University, Sorbonne Paris Cité, EA 4064, Laboratoire Santé Publique et Environnement, Occupational Diseases Dept, University Hospital of Centre of Paris COCHIN, AP-HP, Paris, France. ${ }^{7}$ Hôpital Abderrahmène Mami des Maladies Thoraciques, Paviilon I, Tunis, Tunisia. ${ }^{8}$ Service d'Anatomie Pathologique, Centre Chirurgical Marie Lannelongue, Le Plessis Robinson, France. ' Service de Chirurgie Thoracique et Vasculaire, Centre Chirurgical Marie Lannelongue, Le Plessis Robinson, France. ${ }^{10}$ UMR_S956, Université Pierre et Marie Curie-Paris 6, INSERM, Laboratoire d'Oncogénétique et Angiogénétique Moléculaire, Groupe Hospitalier Pitié-Salpétrière, Paris, France. ${ }^{11}$ Both authors contributed equally to this work.
\end{abstract}

Correspondence: David Montani, Université Paris-Sud, Centre de Référence de l'Hypertension Pulmonaire Sévère, Service de Pneumologie et Réanimation Respiratoire, Hôpital Bicêtre, 78, Rue du général Leclerc, 94270 Le Kremlin-Bicêtre, France. E-mail: david.montaniabct.aphp.fr

ABSTRACT Pulmonary veno-occlusive disease (PVOD) is a rare form of pulmonary hypertension characterised by predominant remodelling of pulmonary venules. Bi-allelic mutations in the eukaryotic translation initiation factor $2 \alpha$ kinase 4 (EIF2AK4) gene were recently described as the major cause of heritable PVOD, but risk factors associated with PVOD remain poorly understood. Occupational exposures have been proposed as a potential risk factor for PVOD, but epidemiological studies are lacking.

A case-control study was conducted in consecutive PVOD (cases, $\mathrm{n}=33$ ) and pulmonary arterial hypertension patients (controls, $\mathrm{n}=65$ ). Occupational exposure was evaluated via questionnaire interview with blinded assessments using an expert consensus approach and a job exposure matrix (JEM).

Using the expert consensus approach, PVOD was significantly associated with occupational exposure to organic solvents (adjusted OR 12.8, 95\% CI 2.7-60.8), with trichloroethylene being the main agent implicated (adjusted OR 8.2, 95\% CI 1.4-49.4). JEM analysis independently confirmed the association between PVOD and trichloroethylene exposure. Absence of significant trichloroethylene exposure was associated with a younger age of disease $(54.8 \pm 21.4$ years, $\mathrm{p}=0.037)$ and a high prevalence of harbouring bi-allelic EIF2AK4 mutations (41.7\% versus $0 \%, \mathrm{p}=0.015$ ).

Occupational exposure to organic solvents may represent a novel risk factor for PVOD. Genetic background and environmental exposure appear to influence the phenotypic expression of the disease.

@ERSpublications

Occupational exposure to organic solvents is a novel risk factor for pulmonary veno-occlusive disease http://ow.ly/StFsk

Received: May 222015 | Accepted after revision: Aug 272015 | First published online: Nov 052015

Conflict of interest: Disclosures can be found alongside the online version of this article at erj.ersjournals.com

Copyright @ERS 2015 


\section{Introduction}

Pulmonary veno-occlusive disease (PVOD) is a rare form of pulmonary hypertension (PH) characterised by progressive occlusion of pulmonary veins by fibrous tissue and intimal thickening, with preferential involvement of venules and small veins within the lobular septa $[1,2]$. In the current $\mathrm{PH}$ classification, PVOD and pulmonary capillary haemangiomatosis $(\mathrm{PCH})$ are classified together as a unified entity as Group 1' $\mathrm{PVOD} / \mathrm{PCH}$, as both conditions share overlapping clinical, histopathological and genetic features, and are considered to represent spectrums of a common disorder $[3,4]$.

The pathogenesis and risk factors associated with the development of PVOD remain poorly understood. Recently, autosomal recessive bi-allelic mutations in the eukaryotic translation initiation factor $2 \alpha$ kinase 4 (EIF2AK4) gene have been identified as the major genetic cause of PVOD/PCH $[5,6]$. EIF2AK4 bi-allelic mutations were identified in all patients with heritable forms of PVOD from the French PH Network and, interestingly, $\sim 25 \%$ of apparently sporadic cases of PVOD were also found to carry bi-allelic EIF2AK4 mutations.

Apart from genetic predisposition, other risk factors have also been identified to be associated with PVOD [7]. These include smoking [8], chemotherapeutic agents (particularly alkylating agents) [9, 10] and connective tissue diseases [11]. Indeed, pulmonary venous involvement is frequently observed in $\mathrm{PH}$ associated with connective tissue diseases [12-14] and as many as $60 \%$ of patients with systemic sclerosis-associated pre-capillary PH may display clinical features consistent with PVOD [13].

Chemical exposure has previously been proposed to be a potential aetiological factor, with case reports suggesting the development of PVOD following various occupational exposures [1, 11]. Accordingly, we have also observed from our clinical experience that some PVOD patients report an occupational history of significant exposure to chemicals such as organic solvents. Furthermore, numerous epidemiological studies have demonstrated an association between exposure to organic solvents and systemic sclerosis [15-17]. Given the above considerations and the aforementioned high frequency of venular involvement in systemic sclerosis-associated pre-capillary $\mathrm{PH}$, we speculated whether occupational exposure to organic solvents might also be relevant in PVOD.

The aim of the present study was to perform a case-control study to evaluate the association between PVOD and occupational exposure to chemicals, particularly organic solvents. Moreover, we were interested to assess whether genetic factors had a modifying effect on this potential association.

\section{Methods}

Study population

This was a case-control study conducted at the National Reference Centre for Severe Pulmonary Hypertension, Le Kremlin Bicêtre, France. Between September 2008 and February 2010, patients above the age of 18 with a diagnosis of PVOD (cases) and idiopathic, anorexigen-induced or heritable pulmonary arterial hypertension (PAH) (controls) were eligible for study participation. To avoid selection bias, consecutive consenting patients with a diagnosis of PVOD or PAH who presented to the outpatient clinic for routine follow-up assessment were invited to participate.

The diagnosis of PAH was made according to current guidelines [18] and all patients had confirmed pre-capillary $\mathrm{PH}$ at diagnostic right heart catheterisation. The diagnosis of PVOD was established according to the following criteria and only patients with either confirmed or highly probable PVOD were recruited. Patients were considered to have confirmed PVOD if a histological specimen (from either lung biopsy, explanted lung or post mortem examination) was consistent with PVOD or they were carriers of bi-allelic mutations in the EFI2AK4 gene. Patients were also deemed to have confirmed PVOD if they presented with highly probable PVOD and developed pulmonary oedema following the initiation of specific PAH therapy. Highly probable PVOD was considered to be present if patients fulfilled at least two of the following three criteria: 1) two or more characteristic radiological signs of PVOD (septal lines, centrilobular ground glass opacities, enlarged mediastinal lymph nodes) on high-resolution computed tomography (HRCT) of the chest, 2) diffusing capacity of the lung for carbon monoxide to alveolar volume ratio ( $\mathrm{DLCO} / \mathrm{VA})<55 \%$ or resting arterial oxygen tension $\left(\mathrm{PaO}_{2}\right)$ on room air $<65 \mathrm{mmHg}$ or 3) presence of alveolar haemorrhage on bronchoalveolar lavage (Golde score $>80$ or haemosiderin-laden macrophages $>30 \%$ ). As ante mortem diagnosis of PVOD with lung biopsy is not usually feasible due to the presence of severe $\mathrm{PH}$, we have previously demonstrated that a noninvasive diagnostic approach based on the above criteria is highly specific for PVOD [1, 8]. Exclusion criteria for both cases and controls included a history of connective tissue disease, portal hypertension, HIV infection, congenital heart disease and thromboembolic disease.

Clinical characteristics of all study subjects, including baseline demographic information, pulmonary haemodynamics, New York Heart Association Functional Class (NYHA FC), 6-min walk distance (6MWD) and lung function testing, were retrieved from the Registry of the French PH Network. This Registry was 
established in accordance with French bioethics laws (Commission Nationale de l'Informatique et des Libertés) and all patients gave informed consent.

\section{Genetic analysis}

Genetic counselling and testing were proposed to both PVOD and PAH patients. PAH and PVOD patients were screened for point mutations and large rearrangements of the bone morphogenetic protein receptor type 2 (BMPR2) gene, the main predisposing factor for heritable PAH. Patients with confirmed or highly probable PVOD were also screened for EIF2AK4 mutations. In the French Referral Centre, BMPR2 mutation testing has been conducted since 2003 and EIF2AK4 mutation testing began in 2013 following the first report of bi-allelic mutations in the EIF2AK4 gene as a cause of heritable PVOD. Eight PVOD patients died before DNA collection was possible for EIF2AK4 testing. Genetic analyses of BMPR2 and EIF2AK4 genes were performed as previously described $[5,19]$. All patients undergoing genetic testing provided written informed consent.

\section{Occupational exposure questionnaire}

Each subject's work history was determined by means of a standardised occupational questionnaire conducted by an experienced interviewer. The questionnaire was designed by a PH physician (D.M.) together with an occupational medicine physician (A.D.). Each job lasting for a period of at least 3 months was recorded, and details included the job title, activity sector and associated tasks. Information on specific job tasks included a complete description of the frequency and duration of the task, the use of protection devices, and direct or indirect exposure to chemicals, dusts, gases or fumes. Subjects were also asked to self-report whether they had specific work or leisure exposure to the following substances: any organic solvents, trichloroethylene, paints, varnish, glues, degreasing agents, plastic resins, detergents, disinfectants, cosmetic products, insecticides, herbicides, epoxy derivatives and silica.

\section{Expert consensus assessment}

In the primary analysis, an expert consensus approach was employed and three occupational medicine physicians (A.D., P.A. and L.B.) blinded to the case or control status of study subjects reviewed each questionnaire. For each job suspected to be associated with a specific exposure, the duration of exposure (number of years) was determined. Recent exposures ( $<10$ years from date of diagnosis) were considered separately, considering plausible latency between exposure and disease development. Weighting factors were attributed for the intensity of exposure (low, intermediate or high level) and the frequency of exposure (sporadic, regular but not often $(<25 \%$ of the working day) and often $(\geqslant 25 \%$ of the working day)). A semi-quantitative exposure category was then built for the assessment of cumulative exposure level: 0 , unexposed; 1, trivial; 2, moderate; 3, high. From this expert consensus approach, an exposure category of 2 or more was considered to be indicative of positive exposure.

\section{Job exposure matrix assessment}

A job exposure matrix (JEM) was also used to evaluate occupational exposures (Matgéné) [20, 21]. Both expert consensus assessment and JEM are commonly used to evaluate occupational exposures [20, 22, 23]. Therefore, these two independent assessment tools were used as complementary analyses to increase the robustness of any positive associations. For JEM analysis, occupations and activity sectors were coded according to the French "Professions et Categories Socioprofessionelles" (1994) and "Nomenclature d'Activités Francaise" (2000). Based on the individual occupation and activity sector, the JEM enables an estimation of cumulative exposure to specific solvent classes (trichloroethylene, white spirits, benzene and aliphatic petroleum solvents). For each solvent class, the JEM provides information on the probability, intensity and frequency of exposure associated with each job. From the JEM, scores was assigned for the probability, intensity and frequency of exposure (1, low; 2, moderate; 3, high). A cumulative exposure index score (CEI) was constructed from the JEM as follows: CEI=probability $\times$ intensity $\times$ frequency $\times$ duration (years). For example, a job considered to have a low probability (score 1), low intensity (score 1) and high frequency (score 3 ) of exposure to trichloroethylene with a duration of 5 years will have a CEI $=1 \times 1 \times 3 \times 5=15$. A CEI $>10$ was considered to be indicative of positive exposure. CEI was calculated with and without adjusting for recent exposure ( $<10$ years from diagnosis). The date of diagnosis was considered to be the date of diagnostic right heart catheterisation.

\section{Statistical analysis}

Results are presented as mean \pm SD unless otherwise stated. Continuous variables were compared with independent sample t-test or Mann-Whitney U-test, as appropriate. Proportions were compared using Chi-squared and Fisher's exact tests. Unconditional logistical regression analyses were performed to assess the association between occupation exposures and PVOD, with multivariate analysis adjusting for the presence of confounding factors. Statistical significance was inferred at $\mathrm{p}<0.05$ and all analysis were performed using SPSS version 22 (IBM, Chicago, IL, USA). 


\section{Results}

Patients

A total of 100 consecutive subjects were recruited (PVOD, n=34; PAH, n=66) and underwent detailed occupational exposure assessment. However, during the course of the study two patients with an initial classification of PVOD and PAH had alternative final diagnoses (systemic sclerosis, $n=1$ and portal hypertension, $n=1$, respectively), resulting in a total of $33 \mathrm{PVOD}$ and $65 \mathrm{PAH}$ patients included in the final analysis.

PVOD patients were older compared with PAH patients $(60.4 \pm 18.1$ versus $50.6 \pm 15.8$ years, $\mathrm{p}=0.0072)$, and a bimodal age distribution was seen in the PVOD group with two apparent peaks occurring at the 20-30 and 70-80 years deciles (figure 1). The younger peak was predominantly represented by patients with heritable PVOD $(n=5)$ harbouring bi-allelic mutations in the EIF2AK4 gene including a mean of age $26.1 \pm 3.6$ years and a sex ratio (male:female) of 3:2. In contrast, the PAH group displayed a unimodal age distribution peaking at the 50-60 years decile.

Compared with PAH, a higher male:female ratio was found in the PVOD group (4.5 versus $0.4, \mathrm{p}<0.001$ ). PVOD patients also had a higher prevalence of significant smoking history of $>5$ pack-years $(78.8 \%$ versus $32.3 \%, \mathrm{p}<0.001)$ as well as higher cumulative smoking exposure $(33.0 \pm 24.7$ versus $8.0 \pm 14.3$ pack-years, $\mathrm{p}<0.0001)$. The association between PVOD and smoking remained significant after adjustment for age and sex.

PVOD patients presented with more severe functional impairment as evidenced by lower 6MWD $(226 \pm 166$ versus $353 \pm 137 \mathrm{~m}, \mathrm{p}=0.0002)$ and higher NYHA FC $(\mathrm{p}=0.082)$, despite less severe haemodynamic impairment at diagnosis compared with PAH patients. Table 1 summarises the baseline characteristics of the study population.

\section{Expert consensus assessment of occupational exposure}

From the primary expert consensus assessment, a significant occupational history of exposure was elicited in $72.7 \%$ of PVOD patients compared with $27.7 \%$ of PAH patients $(\mathrm{p}<0.001)$. When analysis was stratified by male sex only, the association between occupation exposure and PVOD remained significant $(74.1 \%$ versus $25.9 \%, \mathrm{p}=0.016$ ) (figure $2 \mathrm{a}$ and $\mathrm{b}$ ). Of the PVOD patients with a significant exposure history, the most common occupational exposures included any organic solvents (79.2\%), including trichloroethylene (58.3\%), degreasing agents (29.2\%), paints (25.0\%) and varnish/glue (25\%) (figure 3).

Table 2 summarises the association between exposure to specific agents and PVOD. Following adjustment for age, sex and smoking history, both organic solvents and trichloroethylene exposure remained significantly associated with PVOD (adjusted OR for organic solvents 12.8, 95\% CI 2.7-60.8; p=0.001 and adjusted OR for trichloroethylene 8.2, 95\% CI 1.4-49.4; $\mathrm{p}=0.022$ ). The median latency between first exposure to trichloroethylene and PVOD diagnosis was 48 years (interquartile range (IQR) 39-52) with a median exposure duration of 17 years (IQR 9-33). The most common occupations resulting in trichloroethylene exposure included metal workers, mechanics and repairers, building painters, and cleaners.
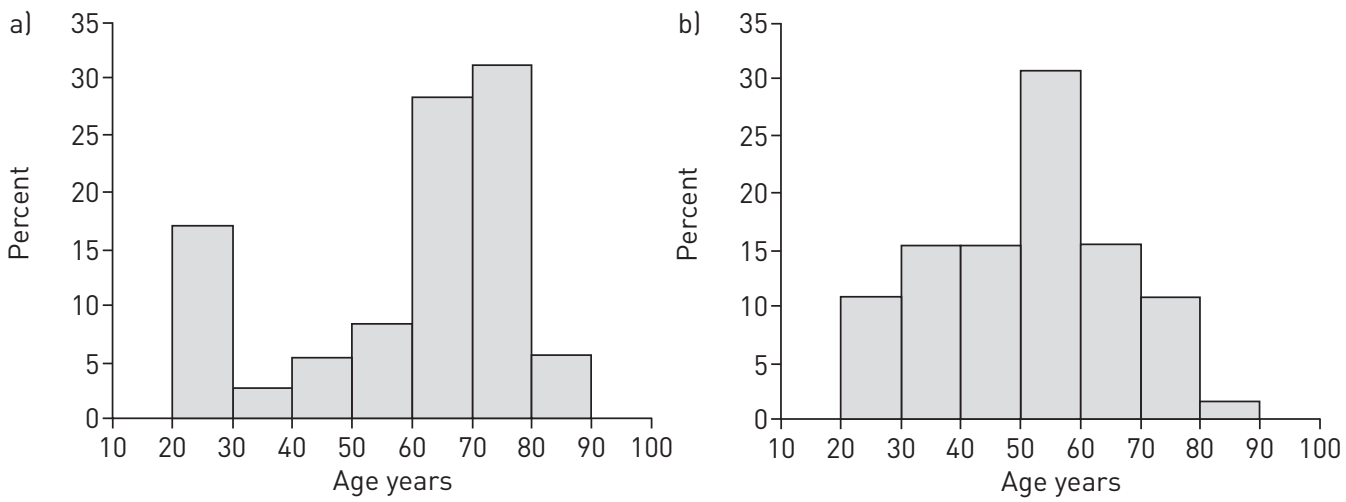

FIGURE 1 Age distribution of a) pulmonary veno-occlusive disease (PVOD; $n=33$ ) and b) pulmonary arterial hypertension ( $\mathrm{PAH} ; \mathrm{n}=65$ ) patients. PVOD patients displayed a bimodal distribution with the first peak occurring at the 20-30 years decile and a later peak at the 70-80 years decile. The first peak corresponded mainly to patients with heritable PVOD carrying bi-allelic mutations in the eukaryotic translation initiation factor $2 \alpha$ kinase 4 (EIF2AK4) gene. In contrast, a unimodal age distribution peaking at the 50-60 years decile was observed in the PAH group. 
TABLE 1 Baseline characteristics of study population

\begin{tabular}{|c|c|c|c|}
\hline & PAH & PVOD & p-value \\
\hline Subjects $n$ & 65 & 33 & \\
\hline Age years & $50.6 \pm 15.8$ & $60.4 \pm 18.1$ & 0.0072 \\
\hline Female/male & $45 / 20$ & $6 / 27$ & $<0.0001$ \\
\hline \multicolumn{4}{|l|}{ Tobacco exposure } \\
\hline Never-smoker & $39(60)$ & $5(15.2)$ & $<0.0001$ \\
\hline Current smoker & $12(18.4)$ & $4(12.1)$ & 0.57 \\
\hline$>5$ pack-years & $21(32.3)$ & $26(78.8)$ & $<0.0001$ \\
\hline Total exposure pack-years & $8.0 \pm 14.3$ & $33.0 \pm 24.7$ & $<0.001$ \\
\hline NYHA FC & & & 0.082 \\
\hline $1 / I I$ & $13(20)$ & $2(6.1)$ & \\
\hline III/IV & $52(80)$ & $31(93.9)$ & \\
\hline 6MWD m & $353 \pm 137$ & $226 \pm 166$ & 0.0002 \\
\hline \multicolumn{4}{|c|}{ Haemodynamics and gas transfer } \\
\hline $\mathrm{mPAP} \mathrm{mmHg}$ & $56.7 \pm 13.0$ & $49.5 \pm 11.5$ & 0.0081 \\
\hline $\mathrm{Cl} \mathrm{L} \cdot \mathrm{min}^{-1} \cdot \mathrm{m}^{-2}$ & $2.52 \pm 1.09$ & $2.44 \pm 0.71$ & 0.73 \\
\hline RAP mmHg & $7.8 \pm 5.1$ & $9.8 \pm 6.2$ & 0.10 \\
\hline PAWP $\mathrm{mmHg}$ & $7.5 \pm 3.7$ & $10.1 \pm 3.4$ & 0.0012 \\
\hline PVR WU & $13.1 \pm 5.1$ & $9.5 \pm 4.2$ & 0.0006 \\
\hline$D \mathrm{Lco} / V_{\mathrm{A}} \%$ pred & $67.0 \pm 23.7$ & $50.5 \pm 22.8$ & 0.0024 \\
\hline \multicolumn{4}{|l|}{ Drug exposure } \\
\hline Anorexigens & $5(7.7)$ & $3(9.1)$ & 0.99 \\
\hline Chemotherapy & $0(0)$ & $2(6.1)$ & 0.11 \\
\hline \multicolumn{4}{|l|}{ Genetic mutation } \\
\hline BMPR2 mutation & $16 / 63(25.4)$ & $0 / 25(0)$ & $<0.0001$ \\
\hline EIF2AK4 mutations & & $5 / 25(20.0)$ & \\
\hline
\end{tabular}

Data are presented as mean \pm SD or $n(\%)$, unless otherwise stated. PAH: pulmonary arterial hypertension; PVOD: pulmonary veno-occlusive disease; NYHA FC: New York Heart Association Functional Class; 6MWD: 6-min walk distance; mPAP: mean pulmonary artery pressure; $\mathrm{Cl}$ : cardiac index; RAP: right arterial pressure; PAWP: pulmonary artery wedge pressure; PVR: pulmonary vascular resistance; $D L C o / V_{A}$ : diffusing capacity for carbon monoxide to alveolar volume ratio; \% pred: \% predicted; BMPR2: bone morphogenetic protein receptor type 2; EIF2AK4: eukaryotic translation initiation factor $2 \alpha$ kinase 4.

\section{Job exposure matrix assessment}

Table 3 summarises the association between PVOD and exposure to four groups of solvents (trichloroethylene, white spirits, benzene and petroleum solvents) using the JEM approach. Trichloroethylene was the only solvent that was significantly associated with PVOD, with and without adjustment for recent exposure (adjusted OR
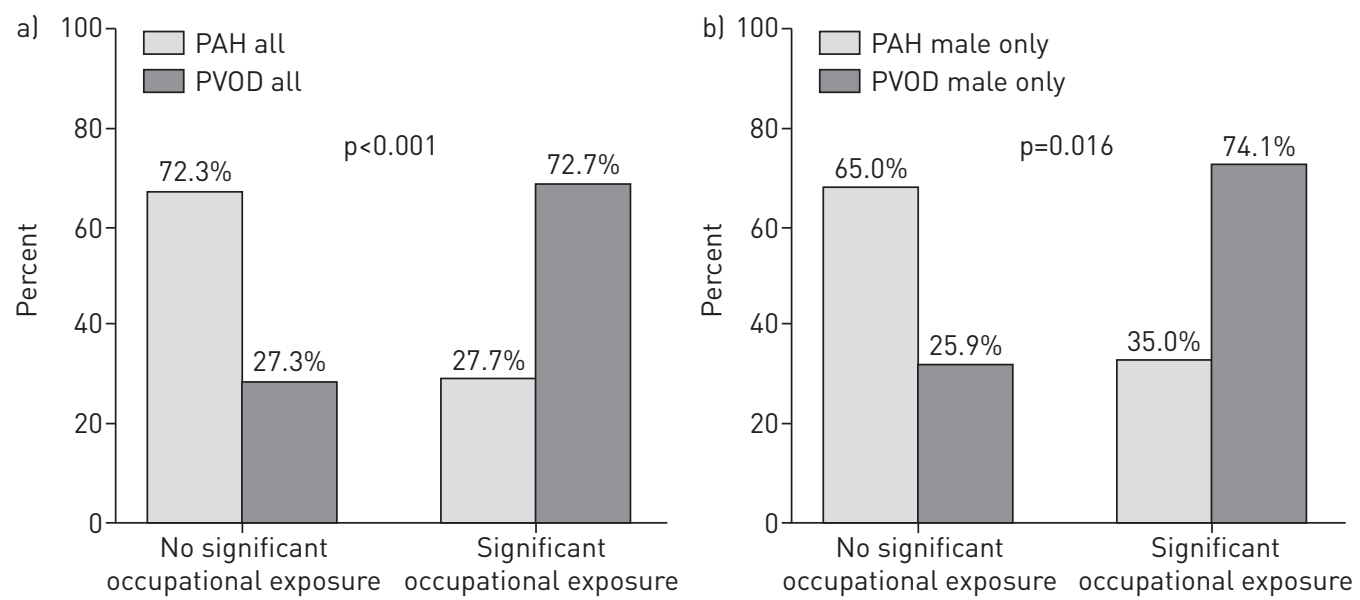

FIGURE 2 Proportion of patients with a significant history of occupational exposures. a) Compared with pulmonary arterial hypertension (PAH), a higher proportion of pulmonary veno-occlusive disease (PVOD) patients had a documented history of occupational exposures (PAH, $n=65 ; P V O D, n=33$ ). b) The relationship remained significant when analysis was stratified by male sex only (PAH, $n=20 ; P V O D, n=27)$. 


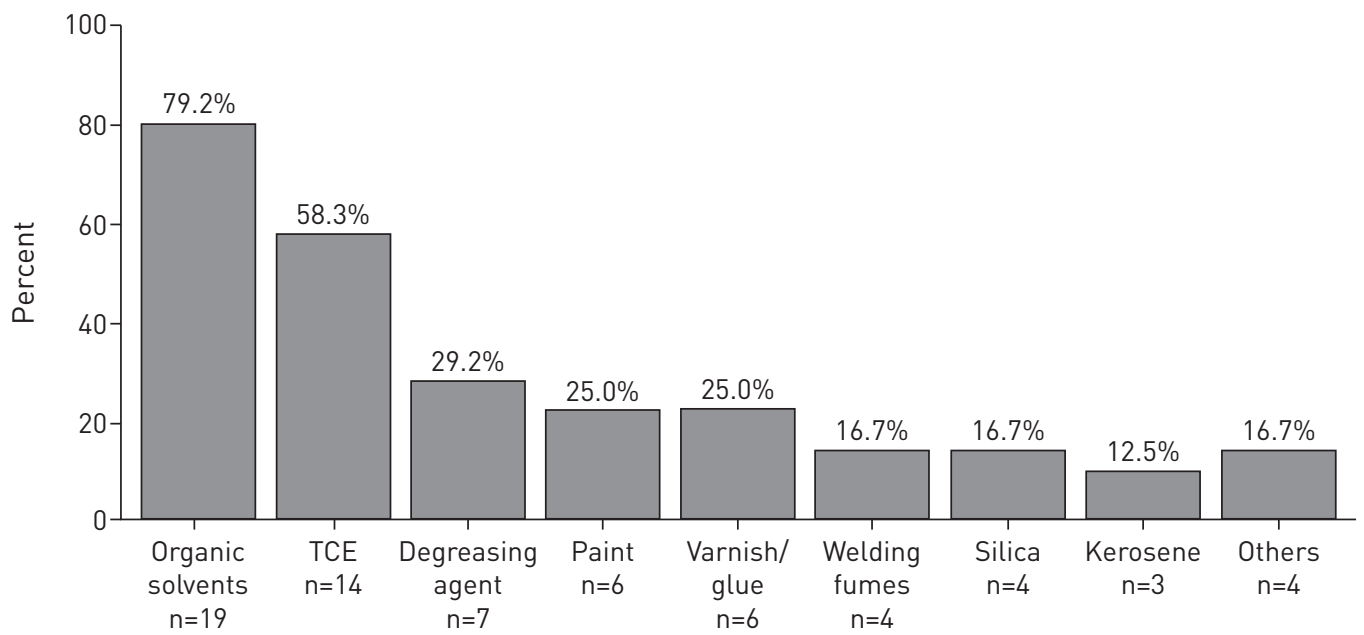

FIGURE 3 Main occupational exposures identified by blinded expert consensus assessment in pulmonary veno-occlusive disease patients ( $n=24)$. TCE: trichloroethylene.

9.8, 95\% CI 1.5-62.3 and 6.4, 95\% 1.3-30.4, respectively; both $\mathrm{p}<0.05)$. The agreement between expert consensus assessment and JEM assessment of exposure to trichloroethylene had a $\kappa$-value of 0.61 .

\section{Relationship between EIF2AK4 mutation and occupational exposure}

Genetic results were available in $88(89.8 \%)$ patients within the entire study cohort (EIF2AK4 mutations screening in $75.8 \%$ of the PVOD group and BMPR2 status in $96.9 \%$ of the PAH group). Five out of 25 (20.0\%) PVOD patients carried bi-allelic mutations in the EIF2AK4 gene, of which two had a familial history of PVOD. No PVOD patients tested positive for the BMPR2 mutation. For the PAH group, 16 out of 63 (25.4\%) harboured heterozygous mutation in the BMPR2 gene (table 1).

As trichloroethylene was the main aetiological agent associated with PVOD identified from both the expert consensus and JEM assessments, we explored whether there were any phenotypic differences in PVOD patients with and without a history of significant exposure to trichloroethylene. PVOD patients who were not significantly exposed to trichloroethylene were younger $(54.8 \pm 21.4$ versus $67.9 \pm 8.1$ years, $\mathrm{p}=0.037)$ and, importantly, they were more likely to harbour EIF2AK4 mutations ( $41.7 \%$ versus $0 \%, \mathrm{p}=0.015$ ). No significant differences in haemodynamics or functional capacity were seen between the trichloroethylene exposed and nonexposed groups. Table 4 summarises the characteristics of PVOD patients stratified by exposure to trichloroethylene.

TABLE 2 Expert consensus assessment of common occupational exposures

\begin{tabular}{|c|c|c|c|c|}
\hline PAH & PVOD & $\begin{array}{l}\text { Crude OR } \\
(95 \% \mathrm{CI})\end{array}$ & $\mathrm{p}$-value & $\begin{array}{c}\text { Adjusted OR } \\
(95 \% \mathrm{Cl})\end{array}$ \\
\hline
\end{tabular}

\begin{tabular}{lcccccc}
\hline Subjects n & 65 & 33 & & & & \\
Any solvents & $4(6.2)$ & $19(57.6)$ & $23.5(6.1-70.4)$ & $<0.0001$ & $12.8(2.7-60.8)$ & 0.001 \\
Trichloroethylene & $2(3.1)$ & $14(42.4)$ & $23.2(4.8-111.3)$ & $<0.0001$ & $8.2(1.4-49.4)$ & 0.022 \\
Paint & $2(3.1)$ & $6(18.2)$ & $7.0(1.3-36.9)$ & 0.022 & $1.7(0.3-10.9)$ & 0.591 \\
Varnish/glue & $2(3.1)$ & $6(18.2)$ & $7.0(1.3-36.9)$ & 0.022 & $2.5(0.3-21.3)$ & 0.398 \\
Detergents & $9(13.8)$ & $3(9.1)$ & $0.62(0.16-2.47)$ & 0.75 & \\
Degreasing agent & $0(0)$ & $7(21.2)$ & Not estimated & 0.0003 & \\
Cosmetic products & $2(3.1)$ & $1(3.0)$ & $0.98(0.09-11.3)$ & 0.99 & \\
Bleach & $6(9.2)$ & $2(6.1)$ & $0.63(0.1-3.3)$ & 0.71 & \\
Kerosene & $0(0)$ & $3(9.1)$ & Not estimated & 0.036 & \\
Welding fumes & $0(0)$ & $4(12.1)$ & Not estimated & 0.011 & \\
Insecticides/herbicides & $2(3.1)$ & $1(3.0)$ & $0.98(0.09-11.3)$ & 0.99 & \\
Epoxy derivatives & $0(0)$ & $0(0)$ & Not estimated & 1.0 & \\
Silica & $0(0)$ & $4(12.1)$ & Not estimated & 0.011 & \\
& & & & &
\end{tabular}

Data are presented as $\mathrm{n}(\%)$, unless otherwise stated. PAH: pulmonary arterial hypertension; PVOD: pulmonary veno-occlusive disease. ${ }^{\#}$ : adjusted for age, sex and smoking history (pack-years). 
TABLE 3 Association between pulmonary veno-occlusive disease (PVOD) and different solvent classes using the job exposure matrix

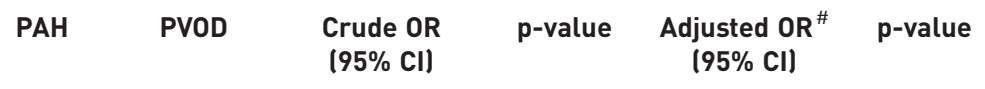

\begin{tabular}{lcccccc}
\hline $\begin{array}{l}\text { Subjects n } \\
\text { Trichloroethylene }\end{array}$ & 65 & 33 & & & & \\
$\quad$ Lifetime exposure & $4(6.2)$ & $12(36.4)$ & $8.7(2.5-30.0)$ & 0.001 & $6.4(1.3-30.4)$ & 0.020 \\
$\quad \begin{array}{l}\text { 10-year lag exposure } \\
\text { White spirits }\end{array}$ & $2(3.1)$ & $12(36.4)$ & $18.0(3.7-87.1)$ & $<0.0001$ & $9.8(1.5-62.3)$ & 0.015 \\
$\quad$ Lifetime exposure & $14(21.5)$ & $13(39.4)$ & $2.4(0.95-5.9)$ & 0.065 & $1.4(0.4-4.8)$ & 0.538 \\
$\quad \begin{array}{l}\text { 10-year lag exposure } \\
\text { Benzene }\end{array}$ & $12(21.5)$ & $13(39.4)$ & $2.8(1.1-7.3)$ & 0.028 & $1.6(0.5-5.2)$ & 0.471 \\
$\quad$ Lifetime exposure & $2(3.1)$ & $3(9.1)$ & $3.2(0.5-19.9)$ & 0.222 & $1.4(0.2-11.8)$ & 0.752 \\
$\quad \begin{array}{l}\text { 10-year lag exposure } \\
\text { Petroleum solvents }\end{array}$ & $1(1.5)$ & $3(9.1)$ & $6.4(0.6-64.1)$ & 0.114 & $2.5(0.2-32.5)$ & 0.484 \\
$\quad$ Lifetime exposure & $1(1.5)$ & $3(9.1)$ & $6.4(0.6-64.1)$ & 0.114 & $2.3(0.2-29.4)$ & 0.529 \\
$\quad$ 10-year lag exposure & $1(1.5)$ & $3(9.1)$ & $6.4(0.6-64.1)$ & 0.114 & $2.3(0.2-29.4)$ & 0.529
\end{tabular}

Data are presented as $\mathrm{n}(\%)$, unless otherwise stated. $\mathrm{PAH}$ : pulmonary arterial hypertension. * : adjusted for age, sex and smoking history (pack-years).

\section{Pathologic assessment of PVOD patients with occupational exposure}

Histologic specimens were available for analysis in seven PVOD patients, including one patient with a history of positive exposure to trichloroethylene. This patient demonstrated venular, capillary and arterial lesions that were typical of PVOD, undistinguishable from idiopathic or heritable PVOD (figure 4).

TABLE 4 Characteristics of pulmonary veno-occlusive disease (PVOD) patients with and without significant exposure to trichloroethylene ${ }^{\#}$

\begin{tabular}{|c|c|c|c|}
\hline & $\begin{array}{l}\text { Absent or trivial } \\
\text { exposure }\end{array}$ & $\begin{array}{l}\text { Intermediate or } \\
\text { high exposure }\end{array}$ & p-value \\
\hline Subjects $\mathrm{n}$ & 19 & 14 & \\
\hline Age years & $54.8 \pm 21.4$ & $67.9 \pm 8.1$ & 0.037 \\
\hline Female/male & $6 / 13$ & $0 / 14$ & 0.027 \\
\hline \multicolumn{4}{|l|}{ Tobacco exposure } \\
\hline Never-smoker & 5 (26.3) & $0(0)$ & 0.057 \\
\hline Current smoker & $3(15.8)$ & $1(7.1)$ & 0.62 \\
\hline$>5$ pack-years & $13(68.4)$ & $13(92.9)$ & 0.20 \\
\hline Total exposure pack-years & $29.0 \pm 26.0$ & $38.4 \pm 22.4$ & 0.29 \\
\hline NYHA FC & & & 1.0 \\
\hline$|/| \mid$ & $1(5.2)$ & $1(7.1)$ & \\
\hline III/IV & $18(94.7)$ & $13(92.9)$ & \\
\hline 6MWD m & $301 \pm 146$ & $245 \pm 110$ & 0.36 \\
\hline \multicolumn{4}{|c|}{ Haemodynamics and gas transfer } \\
\hline $\mathrm{mPAP} \mathrm{mmHg}$ & $48.1 \pm 10.0$ & $51.3 \pm 13.5$ & 0.44 \\
\hline $\mathrm{Cl} \mathrm{L} \cdot \mathrm{min}^{-1} \cdot \mathrm{m}^{-2}$ & $2.3 \pm 0.7$ & $2.6 \pm 0.7$ & 0.29 \\
\hline RAP $\mathrm{mmHg}$ & $8.4 \pm 5.5$ & $11.5 \pm 6.8$ & 0.16 \\
\hline PAWP $\mathrm{mmHg}$ & $10.3 \pm 3.6$ & $9.8 \pm 3.2$ & 0.70 \\
\hline PVR WU & $9.7 \pm 3.7$ & $9.2 \pm 4.9$ & 0.71 \\
\hline$D\left\llcorner c o / V_{A} \%\right.$ pred & $34.4 \pm 11.8$ & $37.8 \pm 14.4$ & 0.49 \\
\hline EIF2AK4 mutations" & $5 / 12(41.7)$ & $0 / 13(0)$ & 0.015 \\
\hline \multicolumn{4}{|c|}{ 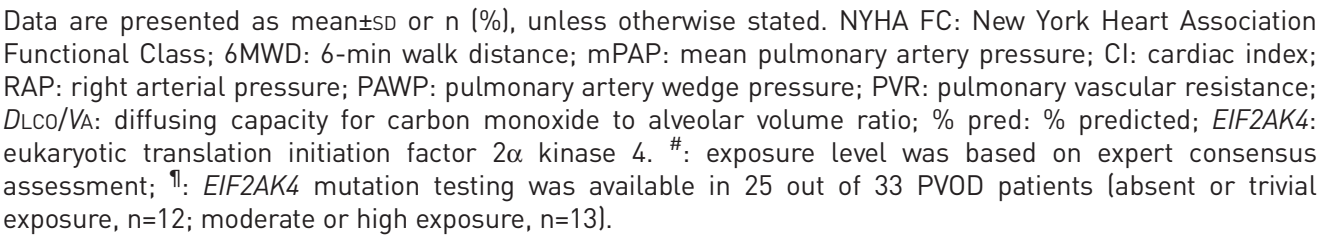 } \\
\hline
\end{tabular}



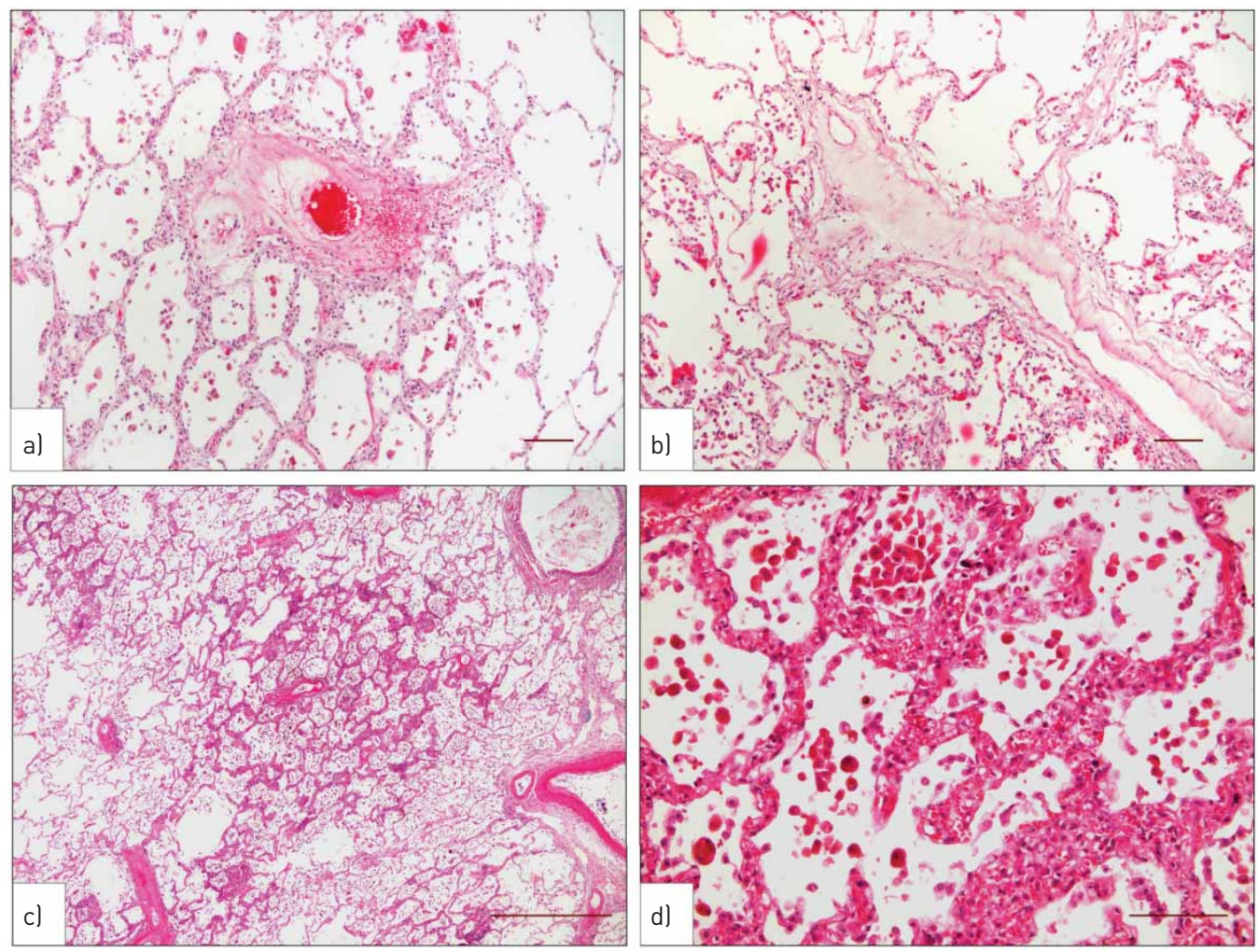

FIGURE 4 Histology from lungs of a patient with pulmonary veno-occlusive disease (PVOD) with positive history of exposure to trichloroethylene without bi-allelic eukaryotic translation initiation factor $2 \alpha$ kinase 4 (EIF2AK4) mutations. a, b) Septal veins and pre-septal venules are obliterated by collagen-rich, loose fibrosis; the parenchyma is otherwise lacking important interstitial remodelling. c) Patchy foci of capillary haemangiomatosis are present on most samples, frequently in association with remodelled pulmonary vessels and microvessels (centre). d) Thickening of alveolar walls is due to a multiplication of capillaries; note the abundance of pigmented macrophages (siderophages) within the alveoli. Scale bars: a, b, d) $100 \mu \mathrm{m}$; c) $1000 \mu \mathrm{m}$.

\section{Discussion}

To the best of our knowledge, the present study represents the largest series of PVOD patients to be reported and is the first to systemically evaluate occupational exposures as a potential risk factor for PVOD using detailed questionnaire interview. We identified an association between occupational exposure to organic solvents and PVOD, with trichloroethylene (a chlorinated solvent) being the main agent implicated in this association. This association was found using two independent methods of exposure assessment, i.e. expert consensus approach and JEM. Moreover, we found distinct phenotypic differences in PVOD patients with and without a history of exposure. Compared with PVOD patients with a history of exposure to trichloroethylene, unexposed patients were younger and had a higher prevalence of harbouring bi-allelic mutations in the EIF2AK4 gene. These findings offer novel insights into the risk factors and pathobiology of PVOD.

PVOD is a rare form of $\mathrm{PH}$ with an estimated annual incidence rate of $\sim 0.1-0.2$ per million $[1,11]$. The defining pathological feature of PVOD is the diffuse involvement of venules and septal veins in a vasculopathy characterised by intimal fibrosis resulting in luminal narrowing or obliteration [2]. The clinical presentation of PVOD can mimic PAH with insidious onset of breathlessness and signs of $\mathrm{PH}$. Compared with $\mathrm{PAH}$, the clinical course of PVOD is usually more aggressive and is characterised by poor response to PAH therapy. In fact, the use of pulmonary vasodilators can be associated with the development of life-threatening pulmonary oedema. Lung transplantation remains the preferred therapy for eligible PVOD patients [1].

Chlorinated organic solvents have been associated with numerous adverse health effects, including acute and chronic neurotoxicity, hepatitis, renal injury, dermatitis haematological effects, and lung cancer [24-26]. Furthermore, solvent exposure has been linked in epidemiological studies to the development of systemic sclerosis, a known cause of PVOD. Although conflicting results have been reported in the literature, a meta-analysis pooling data from 11 studies (1291 patients and 3435 controls) demonstrated a significant association between solvent exposure and systemic sclerosis with an increased OR of 1.8 (95\% CI 1.2-2.5; $\mathrm{p}=0.002$ ) [27]. Furthermore, a previous study by NiERTART et al. [16] found that trichloroethylene was a 
particular risk factor for systemic sclerosis in male patients, especially in those with serological evidence of topoisomerase 1 antibodies. Pre-capillary $\mathrm{PH}$ is a lethal complication of systemic sclerosis with a lifetime risk of $\sim 10 \%$ [28]. Although most cases of pre-capillary PH in systemic sclerosis are attributed as PAH, emerging evidence suggests that pulmonary venous involvement presenting as PVOD is an under-recognised complication [13]. In addition, a recent study highlighted that the majority of patients with systemic sclerosis associated pre-capillary PH demonstrate characteristic radiological features of PVOD on chest HRCT [14]. It remains entirely speculative whether PVOD and systemic sclerosis might represent different spectrums of potential end-organ toxicities associated with organic solvent exposure.

The epidemiology and risk factors associated with the development of PVOD remain poorly understood. The largest series of PVOD patients published to date included only 24 patients [8]. Previous studies have indicated that exposure to toxins such as cigarette smoke and chemotherapeutic agents is associated with the development of PVOD $[8,9]$. The association between smoking and PVOD was confirmed in this study. It is believed that pulmonary endothelial injury is perhaps the common inciting event that underlies the association between toxic exposures and PVOD. However, very little is known regarding the effects of solvents such as trichloroethylene on endothelial cell function. A study by Ou et al. [29] showed that in bovine coronary endothelial cells, trichloroethylene altered endothelial nitric oxide synthase (eNOS) activity and induced eNOS to shift from nitric oxide to superoxide anion generation. However, even if endothelial injury does represent a common mechanistic pathway of toxin exposures, it is unknown why there might be a predilection for pulmonary venular injury rather than arterial injury for these specific exposures.

Recently, bi-allelic mutations in the EIF2AK4 gene coding for a serine/threonine-protein kinase, also known as general control nonderepressible 2 (GCN2), were found to be the major cause of heritable PVOD [5]. GCN2 is a member of a family of eukaryotic initiation factor 2 kinases that become activated in response to diverse cellular stresses. Upon amino acid starvation, GCN2 phosphorylates eukaryotic initiation factor 2, which leads to preferential synthesis of stress proteins [30]. It remains elusive on how loss-of-function mutations in the EIF2AK4 gene are related to pulmonary vascular remodelling and how GCN2 influences vascular homeostasis in different vascular compartments such as arteries or veins.

GCN2 appears important in protecting against liver injury induced by carbon tetrachloride, a chlorinated industrial solvent related to trichloroethylene. GCN2 knockout mice $\left(\mathrm{GCN} 2^{-/-}\right.$) are more susceptible to acute and chronic liver toxicity induced by carbon tetrachloride and increased oxidative stress appears to be a potentially relevant mechanism [31]. GCN2 $2^{-/-}$animals have lower levels of glutathionine peroxidase in the liver [32] and GCN2 activation has antioxidant effects on hepatocytes leading to a decrease in hydrogen peroxide levels [33]. It is of interest that mice exposed to trichloroethylene inhalation demonstrate lung injury with vacuolation of club cells and marked thickening of the capillary endothelium accompanied by a fall in reduced glutathionine content together with a concomitant increase in oxidised glutathionine, which are indicative of oxidative stress [34]. Oxidative stress is known to play a role in vascular remodelling, including $\mathrm{PH}[35,36]$, and might represent an important mechanistic pathway for the development of PVOD. It remains unknown whether environmental exposures to toxins such as cigarette smoke or trichloroethylene have an effect of lung vascular GCN2 function and this should be explored further in animal studies.

Our present study also provides important insights into the potential interaction between gene and environment in the phenotypic manifestation of PVOD. One phenotype appears to be characterised by an older age of disease onset, positive exposure history and absence of EIF2AK4 mutations. In contrast, patients without a history of exposure are younger at diagnosis with a high prevalence of heritable disease. It should be emphasised that the absolute risk of developing PVOD associated with organic solvents and trichloroethylene exposure remains small, as these agents are widely used in many industrial sectors and PVOD remains a rare disease. Individual susceptibility must be important and it is known that polymorphisms in cytochrome P450 (CYP2E1) affect metabolism of trichloroethylene, possibly influencing susceptibility to trichloroethylene-induced toxicity in humans [37]. Finally, the long latency between initial exposure to trichloroethylene and the development of clinically overt PVOD among certain patients suggests that chronic and repeated exposure is probably necessary to induce significant pulmonary venous remodelling.

\section{Study limitations}

Although our study may be considered to be relatively small, PVOD is a rare disease and highly significant associations were found with organic solvents and trichloroethylene exposure, with the acknowledgement that confidence limits of odds ratios were wide due to our sample size. As with all case-control studies, assessment of exposure is subject to recall bias and does not provide any proof of causality between the exposure and disease. Reliable exposure assessment can also be challenging and several methods are available to estimate exposure retrospectively. Therefore, we utilised two separate methods (i.e. expert consensus approach and JEM) to assess occupational exposure in order to increase the robustness of our findings. Although the agreement between the two methods was moderate to good, this is consistent with 
published studies which have also demonstrated moderate agreement when different exposure assessment methodologies are employed $[22,23]$. It should be viewed as reassuring that a positive association between trichloroethylene and PVOD was demonstrated using two independent assessment tools.

PAH patients were younger and had a higher proportion of females, which may bias towards a reduced probability of relevant occupational exposures. However, PVOD remained significantly associated with organic solvents and trichloroethylene after adjustment for age, sex and smoking history. The addition of a population-level control group may also strengthen the findings of our study. At present, no financial compensation has been proposed to exposed patients with PVOD in France and the study was conducted with the understanding that patients will not derive direct benefits from participation. Therefore, it is unlikely that financial motivation or secondary gain would have resulted in reporting bias.

\section{Conclusions}

We demonstrate that occupational exposure to organic solvent and trichloroethylene is associated with PVOD. Genetic background and environmental exposure appear to influence the phenotypic expression of the disease. Clinicians should obtain a detailed history of exposure to organic solvents, particularly trichloroethylene.

\section{References}

1 Montani D, Price LC, Dorfmuller P, et al. Pulmonary veno-occlusive disease. Eur Respir J 2009; 33: 189-200.

2 Pietra GG, Capron F, Stewart S, et al. Pathologic assessment of vasculopathies in pulmonary hypertension. $J$ Am Coll Cardiol 2004; 43: 25S-32S.

3 Simonneau G, Gatzoulis MA, Adatia I, et al. Updated clinical classification of pulmonary hypertension. J Am Coll Cardiol 2013; 62: D34-D41.

4 Lantuejoul S, Sheppard MN, Corrin B, et al. Pulmonary veno-occlusive disease and pulmonary capillary hemangiomatosis: a clinicopathologic study of 35 cases. Am J Surgical Pathol 2006; 30: 850-857.

5 Eyries M, Montani D, Girerd B, et al. EIF2AK4 mutations cause pulmonary veno-occlusive disease, a recessive form of pulmonary hypertension. Nature Genet 2014; 46: 65-69.

6 Best DH, Sumner KL, Austin ED, et al. EIF2AK4 mutations in pulmonary capillary hemangiomatosis. Chest 2014; 145: 231-236.

7 Galie N, Humbert M, Vachiery J-L, et al. 2015 ESC/ERS Guidelines for the diagnosis and treatment of pulmonary hypertension. Eur Respir J 2015; 46: 903-975.

8 Montani D, Achouh L, Dorfmuller P, et al. Pulmonary veno-occlusive disease: clinical, functional, radiologic, and hemodynamic characteristics and outcome of 24 cases confirmed by histology. Medicine 2008; 87: 220-233.

9 Ranchoux B, Gunther S, Quarck R, et al. Chemotherapy-induced pulmonary hypertension: role of alkylating agents. Am J Pathol 2015; 185: 356-371.

10 Perros F, Gunther S, Ranchoux B, et al. Mitomycin-induced pulmonary veno-occlusive disease: evidence from human disease and animal models. Circulation 2015; 132: 834-847.

11 Mandel J, Mark EJ, Hales CA. Pulmonary veno-occlusive disease. Am J Respir Crit Care Med 2000; 162: 1964-1973.

12 Johnson SR, Patsios D, Hwang DM, et al. Pulmonary veno-occlusive disease and scleroderma associated pulmonary hypertension. J Rheum 2006; 33: 2347-2350.

13 Dorfmuller P, Humbert M, Perros F, et al. Fibrous remodeling of the pulmonary venous system in pulmonary arterial hypertension associated with connective tissue diseases. Humam Pathol 2007; 38: 893-902.

14 Gunther S, Jais X, Maitre S, et al. Computed tomography findings of pulmonary venoocclusive disease in scleroderma patients presenting with precapillary pulmonary hypertension. Arthritis Rheum 2012; 64: 2995-3005.

15 Marie I, Gehanno JF, Bubenheim M, et al. Prospective study to evaluate the association between systemic sclerosis and occupational exposure and review of the literature. Autoimmun Rev 2014; 13: 151-156.

16 Nietert PJ, Sutherland SE, Silver RM, et al. Is occupational organic solvent exposure a risk factor for scleroderma? Arthritis Rheum 1998; 41: 1111-1118.

17 Barragan-Martinez C, Speck-Hernandez CA, Montoya-Ortiz G, et al. Organic solvents as risk factor for autoimmune diseases: a systematic review and meta-analysis. PloS One 2012; 7: e51506.

18 Hoeper MM, Bogaard HJ, Condliffe R, et al. Definitions and diagnosis of pulmonary hypertension. J Am Coll Cardiol 2013; 62: D42-D50.

19 Girerd B, Montani D, Coulet F, et al. Clinical outcomes of pulmonary arterial hypertension in patients carrying an ACVRL11 (ALK1) mutation. Am J Respir Crit Care Med 2010; 181: 851-861.

20 Févotte J, Dananché B, Delabre L, et al. Matgéné: a program to develop job-exposure matrices in the general population in france. Ann Occup Hyg 2011; 55: 865-878.

21 Institut de Veille Sanitaire. Exp-pro: Outils d'aide à l'évaluation des expositions professionnelles [Exp-pro: tools for the evaluation of occupational exposures]. http://exppro.invs.sante.fr/exppro/accueil. Date last accessed: March $15,2015$.

22 Bourgkard E, Wild P, Gonzalez M, et al. Comparison of exposure assessment methods in a lung cancer case-control study: performance of a lifelong task-based questionnaire for asbestos and PAHs. Occup Environ Med 2013; 70: 884-891.

23 Offermans NS, Vermeulen R, Burdorf A, et al. Comparison of expert and job-exposure matrix-based retrospective exposure assessment of occupational carcinogens in the Netherlands cohort study. Occup Environ Med 2012; 69: $745-751$.

24 Baker EL. A review of recent research on health effects of human occupational exposure to organic solvents. A critical review. J Occup Med 1994; 36: 1079-1092.

25 Ruder AM, Yiin JH, Waters MA, et al. The upper midwest health study: gliomas and occupational exposure to chlorinated solvents. Occup Environ Med 2013; 70: 73-80. 

Mattei F, Guida F, Matrat M, et al. Exposure to chlorinated solvents and lung cancer: results of the ICARE study. Occup Environ Med 2014; 71: 681-689.

27 Kettaneh A, Al Moufti O, Tiev KP, et al. Occupational exposure to solvents and gender-related risk of systemic sclerosis: a metaanalysis of case-control studies. J Rheum 2007; 34: 97-103.

28 Hachulla E, Gressin V, Guillevin L, et al. Early detection of pulmonary arterial hypertension in systemic sclerosis: a French nationwide prospective multicenter study. Arthritis Rheum 2005; 53: 3792-3800.

29 Ou Z, McCarver DG, Hines RN, et al. Trichloroethylene decreases heat shock protein 90 interactions with endothelial nitric oxide synthase: implications for endothelial cell proliferation. Toxicol Sci 2003; 73: 90-97.

30 Donnelly N, Gorman AM, Gupta S, et al. The EIF2alpha kinases: their structures and functions. Cell Mol Life Sci 2013; 70: 3493-3511.

31 Arriazu E, Ruiz de Galarreta M, Lopez-Zabalza MJ, et al. GCN2 kinase is a key regulator of fibrogenesis and acute and chronic liver injury induced by carbon tetrachloride in mice. Lab Invest 2013; 93: 303-310.

32 Chaveroux C, Lambert-Langlais S, Parry L, et al. Identification of GCN2 as new redox regulator for oxidative stress prevention in vivo. Biochem Biophys Res 2011; 415: 120-124.

33 Arriazu E, Perez de Obanos MP, Lopez-Zabalza MJ, et al. Amino acid deprivation decreases intracellular levels of reactive oxygen species in hepatic stellate cells. Cell Physiol Biochem 2010; 26: 281-290.

34 Giovanetti A, Rossi L, Mancuso M, et al. Analysis of lung damage induced by trichloroethylene inhalation in mice fed diets with low, normal, and high copper content. Toxicol Pathol 1998; 26: 628-635.

35 Dorfmuller P, Chaumais MC, Giannakouli M, et al. Increased oxidative stress and severe arterial remodeling induced by permanent high-flow challenge in experimental pulmonary hypertension. Respir Res 2011; 12 : 119.

36 Fortuno A, San Jose G, Moreno MU, et al. Oxidative stress and vascular remodelling. Exp Physiol 2005; 90: 457-462.

37 Lipscomb JC, Garrett CM, Snawder JE. Cytochrome P450-dependent metabolism of trichloroethylene: interindividual differences in humans. Toxicol Appl Pharmacol 1997; 142: 311-318. 